\title{
Randomised, non-comparative phase II study of weekly docetaxel with cisplatin and 5-fluorouracil or with capecitabine in oesophagogastric cancer: the AGITG ATTAX trial
}

\section{NC Tebbutt ${ }^{*}, 1$, MM Cummins ${ }^{2}$, T Sourjina ${ }^{2}$, A Strickland ${ }^{3}$, G Van Hazel ${ }^{4}$, V Ganju ${ }^{5}$, D Gibbs ${ }^{6}$, M Stockler ${ }^{2}$, V Gebski ${ }^{2}$ and J Zalcberg ${ }^{7}$ on behalf of the Australasian Gastro-Intestinal Trials Group}

'Department of Medical Oncology, Austin Health, PO Box 5555, Studley Road, Heidelberg, Melbourne, Victoria 3084, Australia; ${ }^{2}$ National Health and Medical Research Council Clinical Trials Centre, University of Sydney, Locked Bag 77, Camperdown, Sydney, New South Wales 1450 , Australia; ${ }^{3}$ Monash Medical Centre, 246 Clayton Road, Clayton, Melbourne, Victoria 3168, Australia; ${ }^{4}$ Sir Charles Gairdner Hospital, Hospital Avenue, Nedlands, Perth, Western Australia 6009, Australia; ${ }^{5}$ Frankston Hospital, PO Box 52, Frankston, Melbourne, Victoria 3199, Australia; ${ }^{6}$ Christchurch Hospital, 2 Riccarton Avenue, Addington, Christchurch, Canterbury 801 I. New Zealand; ${ }^{7}$ Peter MacCallum Cancer Centre, St Andrews Place, East Melbourne, Melbourne, Victoria 3002, Australia

BACKGROUND: Docetaxel administered 3-weekly with cisplatin and 5-fluorouracil leads to better survival than does standard therapy in patients with oesophagogastric cancer, but leads to high rates of haematological toxicity. Weekly docetaxel is associated with less haematological toxicity. This randomised phase II study tested weekly docetaxel-based combination chemotherapy regimens, with the aim of maintaining their activity while reducing toxicity.

METHODS: Patients with histologically confirmed metastatic oesophageal or gastric carcinoma were randomised to receive weekly docetaxel $\left(30 \mathrm{mg} \mathrm{m}^{-2}\right)$ on days I and 8 , cisplatin $\left(60 \mathrm{mg} \mathrm{m}^{-2}\right)$ on day I, and 5-fluorouracil $\left(200 \mathrm{mg} \mathrm{m}^{-2}\right.$ per day) continuously, every 3 weeks (weekly TCF, wTCF); or docetaxel $\left(30 \mathrm{mg} \mathrm{m}^{-2}\right.$ ) on days I and 8 and capecitabine $\left(1600 \mathrm{mg} \mathrm{m}^{-2}\right.$ per day) on days I- I4, every 3 weeks (weekly TX, wTX).

RESULTS: A total of 106 patients were enrolled (WTCF, $n=50 ;$ wTX, $n=56$ ). Response rates, the primary end point, were $47 \%$ with WTCF and $26 \%$ with wTX. Rates of febrile neutropenia were low in each arm. Median progression-free and overall survival times were 5.9 and II.2 months for WTCF and 4.6 and 10.1 months for wTX, respectively.

CONCLUSION: Weekly TCF and TX have encouraging activity and less haematological toxicity than TCF administered 3-weekly. Weekly docetaxel-based combination regimens warrant further evaluation in this disease.

British Journal of Cancer (2010) I 02, 475-48I. doi:I0.1038/sj.bjc.6605522 www.bjcancer.com

Published online 12 January 2010

(c) 2010 Cancer Research UK

Keywords: advanced gastric cancer; advanced oesophageal cancer; cisplatin; 5-fluorouracil; capecitabine; docetaxel

Oesophagogastric cancer is a major public health problem and is the fourth highest cause of cancer-related mortality globally (Kamangar et al, 2006). Although chemotherapy can improve survival and maintain quality of life for patients with advanced oesophagogastric cancer (Glimelius et al, 1995), optimal chemotherapy for this disease has not been defined.

A recent randomised phase III study showed that adding docetaxel to cisplatin and 5-FU (TCF) improved response rates, progression-free survival (PFS) times, and overall survival (OS) (Van Cutsem et al, 2006). Although the TCF regimen improved clinical outcomes, it was also associated with toxicity, particularly that related to myelosuppression, with a $29 \%$ incidence of febrile neutropenia or neutropenic infection.

Several studies have compared weekly with 3-weekly treatment with docetaxel. Weekly docetaxel is associated with minimal myelosuppression, but with a higher rate of cumulative fatigue,

\footnotetext{
* Correspondence: Associate Professor NC Tebbutt;

E-mail: niall.tebbutt@ludwig.edu.au

Received 8 July 2009; revised 25 November 2009; accepted 4 December 2009; published online 12 January 2010
}

tearing, and nail toxicity (Engels and Verweij, 2005). We postulated that combination regimens using weekly docetaxel may provide palliative benefit for patients with advanced oesophagogastric cancer. As there is potential synergy between docetaxel and capecitabine (Nadella et al, 2002), thought to be mediated through activation of thymidine phosphorylase by docetaxel, we also aimed to explore the activity of a doublet regimen, thereby avoiding the potential toxicity of cisplatin. We therefore evaluated two novel regimens based on weekly docetaxel in a randomised phase II design called the ATTAX study (A randomised phase Two study evaluating a weekly schedule of doceTAXel with cisplatin and 5-FU (weekly TCF, wTCF) or with capecitabine (weekly TX, wTX) in advanced oesophagogastric cancer).

\section{PATIENTS AND METHODS}

\section{Eligibility}

The ATTAX study was conducted according to a protocol reviewed and approved by the Australasian Gastro-Intestinal Trials Group (AGITG), and reviewed and approved by the Human Research 
Ethics Committee of each participating institution. All patients provided written informed consent.

Patients were eligible if they were 18 years of age or older with a histologically confirmed diagnosis of oesophageal, gastric, or oesophagogastric junction carcinoma (squamous, adenocarcinoma or undifferentiated), and of metastatic disease that was unidimensionally measurable according to the Response Evaluation Criteria in Solid Tumours (RECIST). Inclusion of oesophageal, oesophagogastric, and gastric cancers is justified by data showing comparable outcomes for these diseases (Chau et al, 2009a). Similarly, outcomes for patients with advanced squamous cell carcinoma are not significantly different from those for patients with adenocarcinoma (Chau et al, 2007). Patients were not allowed to have had previous anticancer treatment, except for adjuvant radiotherapy or chemotherapy completed at least 12 months before. Further inclusion criteria included WHO performance status (PS) of 0,1 , or 2 (PS2 patients were required to have serum albumin of at least $\left.30 \mathrm{gl}^{-1}\right)$; adequate bone marrow function, including platelets $\left(>100 \times 10^{9}\right.$ cells per l) and neutrophils $\left(>1.5 \times 10^{9}\right.$ cells per 1$)$; normal renal function, including normal serum creatinine and calculated creatinine clearance of at least $50 \mathrm{ml} \mathrm{min}^{-1}$; and adequate hepatic function, including serum total bilirubin $<1.25 \times$ upper limit of normal range, alanine transaminase or aspartate transaminase $<2.5 \times$ upper limit of normal range, and alkaline phosphatase $<5 \times$ upper limit of normal range. In addition, patients had to be able to swallow tablets, have a life expectancy of more than 12 weeks, and have no concurrent uncontrolled medical conditions and no previous malignant disease other than non-melanotic skin cancer or carcinoma in situ of the uterine cervix or other cancers treated with curative intent at least 5 years previously and without evidence of relapse. Patients were required to have a negative pregnancy test and had to agree to practise adequate contraception.

Exclusion criteria included medical or psychiatric conditions that compromised the patient's ability to give informed consent or comply with the study protocol, metastatic disease of the central nervous system, pregnancy or breastfeeding, clinical evidence of peripheral neuropathy of $>$ grade II, and significant deafness or uncontrolled tinnitus. Patients with any uncontrolled concurrent medical condition, known malabsorption syndrome, or who had participated in an investigational drug study within 4 weeks were also excluded from participation in the study.

\section{Randomisation, stratification and treatment}

The ATTAX study was a randomised, phase II, open-label, multicentre study of wTCF or wTX. Randomisation was carried out centrally at the coordinating centre, and patients were stratified by WHO PS $(0,1$ vs 2$)$ and institution.

Patients were randomly assigned in equal proportions to receive either docetaxel (Taxotere; Sanofi-Aventis, Paris, France) $\left(30 \mathrm{mg} \mathrm{m}^{-2}\right)$ on days 1 and 8 , cisplatin $\left(60 \mathrm{mg} \mathrm{m}^{-2}\right)$ on day 1 , and 5-fluorouracil ( $200 \mathrm{mg} \mathrm{m}^{-2}$ per day) by continuous infusion, every 3 weeks (wTCF); or docetaxel $\left(30 \mathrm{mg} \mathrm{m}^{-2}\right)$ on days 1 and 8 and oral capecitabine (Xeloda; Roche, Basel, Switzerland) $\left(800 \mathrm{mg} \mathrm{m}^{-2}\right)$ twice daily on days $1-14$, every 3 weeks (wTX). The dosages were selected for the combination regimens with reference to earlier phase I or II studies (Chen et al, 2002; Lee et al, 2006; Mrozek et al, 2006). Premedication of dexamethasone $(8 \mathrm{mg})$ was given before docetaxel administration, and cisplatin hydration was given according to each investigator's routine practice. Dose-modification criteria were defined in the protocol. Treatment continued for eight cycles in the absence of disease progression, any request by the patient or physician to discontinue therapy, unacceptable toxicity, pregnancy, or serious systemic allergic reaction to any of the study drugs. At the investigator's discretion, patients with no disease progression or grade III or IV toxicity could continue beyond eight cycles. Patients in the wTCF arm experiencing auditory or peripheral neurotoxicity or renal impairment, thought to be related to cisplatin, were allowed to substitute carboplatin for cisplatin.

\section{Evaluation and outcomes}

Before randomisation, each patient was assessed by complete physical examination, full blood count, clotting profile, blood biochemistry, tumour markers (carcinoembryonic antigen (CEA) and carbohydrate antigen (CA 19.9)), 12-lead electrocardiogram, contrast-enhanced CT scan of the thorax, abdomen, and pelvis, and a pregnancy test for women of child-bearing potential.

Subsequently, complete physical examination, blood biochemistry, and a toxicity and adverse event assessment were repeated before each cycle began; a full blood count was repeated before every docetaxel infusion. A tumour marker assessment and contrast-enhanced CT scan of the thorax, abdomen, and pelvis were repeated at the end of every second treatment cycle, then 12 -weekly until disease progression.

Toxicity was graded according to the National Cancer Institute Common Terminology Criteria for Adverse Events (NCI CTCAE), version 3.0 .

Quality of life was assessed using the European Organisation for Research and Treatment of Cancer Quality-of-Life Questionnaire (QLQ) C30, version 3.0 (01 February 2003), together with the oesophageal-specific module (OES 18) or the gastric module (STO 22). Patients with tumours involving the oesophagogastric junction completed the oesophageal module. Questionnaires were completed 3-weekly for the first 12 weeks, then 6-weekly until the completion of chemotherapy, then 12-weekly until disease progression.

After permanent discontinuation of study treatment, patients were assessed for progression status (until documented disease progression), commencement of non-study treatment, and survival status every 12 weeks until death.

\section{Statistical analysis}

The primary clinical end point of the study was response rate, as assessed by RECIST. Secondary end points were OS, PFS, treatment-related toxicity, disease-associated symptoms, and quality of life.

Although randomisation was used to allocate patients to either the wTCF or wTX arm, no comparisons between treatment regimens were planned. The purpose of randomisation was to reduce bias due to patient selection into either treatment arm.

Overall survival was measured from the date of randomisation to the date of death from any cause. Progression-free survival was measured from the date of randomisation to the first evidence of disease progression or the date of death if progression was not previously documented. Time-to-event parameters were estimated using the Kaplan-Meier method. Disease-associated symptoms were derived from the QLQs.

The study used Simon's two-stage design in each arm. For each arm, the first stage required more than five confirmed responses (complete or partial) in the first 21 patients. The second stage involved complete accrual to 50 patients per treatment arm.

Each treatment was expected to achieve a response rate of $37 \%$, which was considered clinically worthwhile and consistent with previous studies using docetaxel. The lowest limit of therapeutic effect considered to be of interest was a response rate of $17 \%$. On the basis of these limits, and $90 \%$ power and a $95 \%$ confidence level, 13 or more responses (complete or partial) per treatment arm were required to determine that a regimen was active.

\section{Study monitoring}

An independent data and safety monitoring board reviewed the safety data after 15 and 25 patients had been enrolled in each 
treatment arm. The tumour response of each patient was centrally reviewed by the lead study clinician and a clinician independent of the study. A total of $7 \%$ of patients at $14 \%$ of institutions were audited by an independent auditor. No significant protocol discrepancies or deviations were noted.

\section{RESULTS}

\section{Patient characteristics}

Between June 2004 and May 2006, 106 patients were randomised (wTCF, 50 patients; wTX, 56 patients) from 19 institutions in Australia and 1 in New Zealand. Two patients were ineligible (no measurable disease), two patients did not commence treatment (one died and one withdrew consent), and two patients did not have any subsequent valid RECIST tumour assessments (Figure 1). The 100 patients who commenced treatment, who had measurable disease, and were assessed according to RECIST, were included in the response-rate analysis. All 106 patients randomised to the study were included in the PFS and OS analyses on an intention-totreat basis. The 104 patients who commenced study treatment were included in the toxicity analyses. The 99 patients who completed the QLQs were included in the disease-related symptoms and quality-of-life analyses.

Baseline characteristics were well balanced between the treatment arms (Table 1).

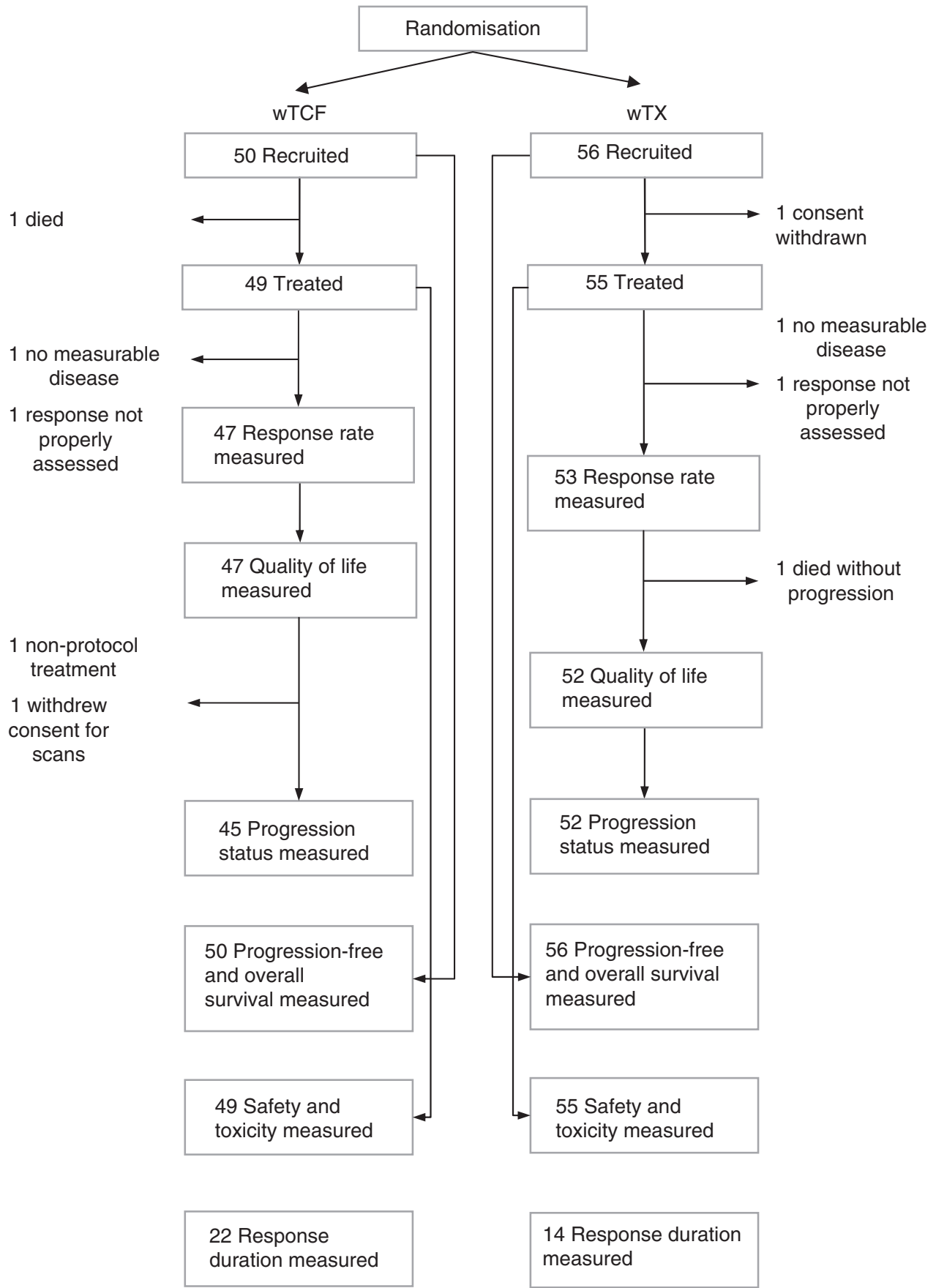

Figure I Enrolment and analysis in the ATTAX study. WTCF= weekly docetaxel, plus cisplatin and 5-fluorouracil; wTX=weekly docetaxel plus capecitabine. 
Table I Patient and cancer baseline characteristics

\begin{tabular}{|c|c|c|c|c|}
\hline \multirow[b]{2}{*}{ Characteristic } & \multicolumn{2}{|c|}{ WTCF $(n=50)$} & \multicolumn{2}{|c|}{ wTX $(n=56)$} \\
\hline & No. & $\%$ & No. & $\%$ \\
\hline \multicolumn{5}{|l|}{ Age (years) } \\
\hline Mean (standard deviation) & \multirow{2}{*}{\multicolumn{2}{|c|}{$\begin{array}{c}60.5(11.5) \\
35-82\end{array}$}} & \multirow{2}{*}{\multicolumn{2}{|c|}{$\begin{array}{c}59.1(10.8) \\
32-79\end{array}$}} \\
\hline Range & & & & \\
\hline \multicolumn{5}{|l|}{ Gender } \\
\hline Male & 42 & 84 & 42 & 75 \\
\hline \multicolumn{5}{|l|}{ WHO performance status } \\
\hline 0 & 21 & 42 & 31 & 55 \\
\hline I & 28 & 56 & 23 & 41 \\
\hline 2 & I & 2 & 2 & 4 \\
\hline \multicolumn{5}{|l|}{ Primary site } \\
\hline Oesophagus & 11 & 22 & 20 & 36 \\
\hline Oesophagogastric junction & 13 & 26 & 13 & 23 \\
\hline Gastric & 26 & 52 & 23 & 41 \\
\hline \multicolumn{5}{|l|}{ Disease status } \\
\hline Local recurrence & 2 & 4 & 5 & 9 \\
\hline \multicolumn{5}{|l|}{ Histology } \\
\hline Squamous cell carcinoma & 2 & 4 & 9 & 16 \\
\hline Adenocarcinoma & 47 & 94 & 45 & 80 \\
\hline Undifferentiated & । & 2 & 2 & 4 \\
\hline \multicolumn{5}{|l|}{ Sites of metastasis } \\
\hline Nodal & 30 & 61 & 41 & 73 \\
\hline Liver & 25 & 51 & 28 & 50 \\
\hline Pulmonary & 7 & 15 & 15 & 27 \\
\hline Peritoneal & 10 & 20 & 6 & 11 \\
\hline Bone & 5 & 10 & 7 & 13 \\
\hline \multicolumn{5}{|l|}{ Number of metastatic organs } \\
\hline । & 24 & 48 & 21 & 38 \\
\hline 2 & 19 & 38 & 24 & 43 \\
\hline 3 & 3 & 6 & 6 & 11 \\
\hline 4 & 3 & 6 & 5 & 9 \\
\hline \multicolumn{5}{|l|}{ RMH prognostic index } \\
\hline Good & 12 & 24 & 19 & 34 \\
\hline Moderate & 37 & 74 & 36 & 64 \\
\hline Poor & । & 2 & I & 2 \\
\hline \multicolumn{5}{|l|}{ Received before adjuvant treatment } \\
\hline Adjuvant radiotherapy & 2 & 4 & I & 2 \\
\hline
\end{tabular}

Abbreviations: $\mathrm{WHO}=$ World Health Organization; $\mathrm{WTCF}=$ weekly docetaxel plus cisplatin and 5-fluorouracil; wTX = weekly docetaxel plus capecitabine.

\section{Treatment}

The median number of cycles delivered per patient was 6 cycles of wTCF (range, 1-8) and 5 cycles of wTX (range, 1-14). Dose intensities compared with the starting dosages in the wTCF arm were docetaxel, 92\%; cisplatin, 91\%; and 5-FU, 98\%. In the wTX arm, they were docetaxel, $98 \%$ and capecitabine, 93\%. Four patients in the wTCF arm had cisplatin-related toxicity and subsequently substituted carboplatin for cisplatin. Treatment delays of more than 1 week occurred for 10 patients $(29 \%)$ in the wTCF arm and for 4 patients (7\%) in the wTX arm.

\section{Efficacy}

Interim response analysis was carried out after 21 patients were recruited to each treatment arm. There were 11 partial responses in the wTCF arm and 5 partial responses in the wTX arm, meeting the
Table 2 Best overall response rates in 100 evaluable patients

\begin{tabular}{|c|c|c|}
\hline & $\begin{array}{c}\text { wTCF (\%) } \\
\text { (95\% CI) }\end{array}$ & $\begin{array}{l}\text { wTX (\%) } \\
(95 \% \text { CI) }\end{array}$ \\
\hline Tumour response & $(n=47)$ & $(n=53)$ \\
\hline Confirmed complete response & 4 & 0 \\
\hline Confirmed partial response & 43 & 26 \\
\hline Confirmed complete or partial response & $47(32-62)$ & $26(15-40)$ \\
\hline Stable disease & 38 & 53 \\
\hline Progressive disease & 15 & 21 \\
\hline
\end{tabular}

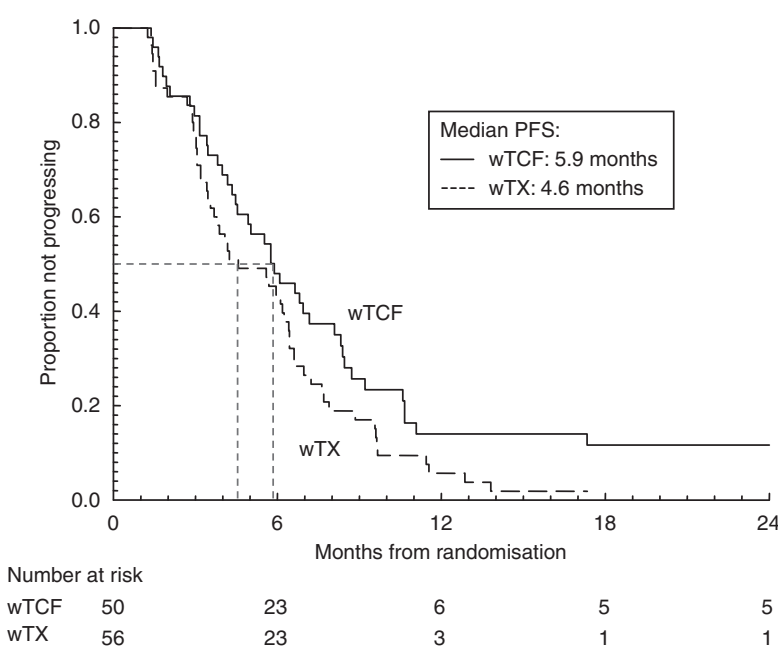

Figure 2 Kaplan-Meier curves of progression-free survival for advanced oesophagogastric cancer patients treated with weekly docetaxel, plus cisplatin and 5-fluorouracil (WTCF; $n=50$ ), or weekly docetaxel with capecitabine ( $w T X ; n=56)$.

criterion of at least 5 responses per treatment arm for the study to continue.

A total of 106 patients were recruited, and the final response analysis was performed 12 months after the last patient was randomised. Of the 47 patients assessable for response in the wTCF arm, 2 had complete response, 20 had partial response, and 18 had stable disease. Of the 53 assessable patients in the wTX arm, none had complete response, 14 had partial response, and 28 had stable disease (Table 2). The confirmed overall response rates were $47 \%$ (95\% CI, $32-62 \%$ ) for wTCF and $26 \%$ (95\% CI, $15-40 \%)$ for wTX.

At the median follow-up time of 40.7 months, 92 patients had progressed, two could not be assessed for progression (one commenced non-protocol treatment before progression and one withdrew consent for further CT scans), whereas four patients in the wTCF arm and one patient in the wTX arm had not progressed. The median durations for response were 6.45 months for wTCF and 6.74 months for wTX.

At the time of analysis, 98 patients had died. Median PFS times were 5.9 months for wTCF and 4.6 months for wTX (Figure 2). Median OS times were 11.2 months for wTCF and 10.1 months for wTX (Figure 3).

\section{Toxicity}

Toxicity in the 104 patients who commenced treatment is summarised in Table 3. Three patients on wTCF and one on wTX had grade III febrile neutropenia; both rates are significantly 
less than the rates observed with 3-weekly docetaxel-based chemotherapy regimens. The most significant common adverse events in the wTCF arm were grade III or IV diarrhoea, grade III or IV fatigue, grade III stomatitis, grade III anorexia, and grade III nausea. The most significant common adverse events in the wTX arm were grade III nausea, grade III vomiting, grade III diarrhoea, grade III anorexia, and grade III fatigue.

Mortality from any cause at 60 days was $6 \%$ in the wTCF arm (three patients; $95 \% \mathrm{CI}, 0.7-11.3 \%)$ and $0 \%$ in the wTX arm $(95 \%$ CI, 0-6\%). There were no treatment-related deaths.

\section{Disease-associated symptoms and quality of life}

Improvement in a specific disease-associated symptom or an aspect of quality of life was defined as an increase of 10 points or more for that questionnaire item for more than 3 weeks. For wTCF and $\mathrm{wTX}$, improvement in global health and quality of life was seen in $30 \%$ and $35 \%$ of patients, in nausea and vomiting in $30 \%$ and

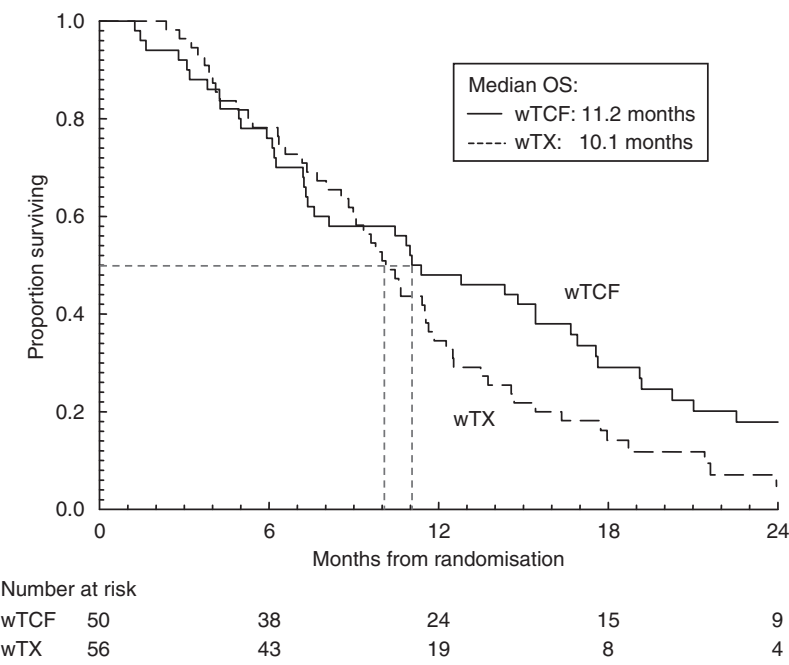

Figure 3 Kaplan-Meier curves of overall survival for advanced oesophagogastric cancer patients treated with weekly docetaxel along with cisplatin and 5-fluorouracil (WTCF; $n=50$ ), or weekly docetaxel with capecitabine ( $W T X ; n=56$ )
$31 \%$, in fatigue in $36 \%$ and $46 \%$, and in pain in $47 \%$ and $50 \%$, respectively. The most striking improvement was in dysphagia in patients with oesophageal disease, among whom $71 \%$ and $70 \%$ treated with wTCF and wTX improved, respectively, compared with $46 \%$ and $41 \%$ of patients with gastric disease, respectively.

\section{DISCUSSION}

This randomised phase II study has shown that it is feasible to develop combination chemotherapy regimens incorporating weekly docetaxel for advanced oesophagogastric cancer. There is clear evidence that docetaxel has non-cross-resistant activity in advanced oesophagogastric cancer. Docetaxel has efficacy as a single agent after failure of platinum and fluoropyrimidines, as well as additive activity when used in combination with cisplatin and 5-FU (Cascinu et al, 2001; Van Cutsem et al, 2006). However, significant myelosuppression with 3-weekly administration poses a major problem for the development of combination chemotherapy regimens, because the myelosuppressive effects add to the toxicities of other chemotherapy agents. The most striking change in the safety profile of the weekly docetaxel-based combination regimens used in this study was a substantially lower rate of myelosuppression and complicated neutropenia compared with that of 3-weekly TCF (Van Cutsem et al, 2006). This occurred despite the somewhat older population of patients (the median age in both arms was over 60 years) in this study, whereas older patients have higher rates of toxicity with 3-weekly TCF (Van Cutsem et al, 2006). Cumulative toxicities related to docetaxel, such as fatigue and tearing, did not occur at high frequency in either treatment arm. In addition to modifying the docetaxel schedule, both regimens involved an altered fluoropyrimidine schedule (either continuous-infusion 5FU or capecitabine) compared with 3-weekly TCF, which used a 4-day infusion of high-dose 5FU. This may also have contributed to lower rates of myelosuppression, as other studies have shown more manageable rates of haematological toxicities with protracted infusion schedules of 5FU (Thuss-Patience et al, 2005).

We showed clear evidence of efficacy of both regimens, with PFS and $O S$ times that seem promising. Although cross-study comparisons are problematic, the population enrolled did not seem to have more favourable demographic features than those in the study by Van Cutsem et al, (2006); hence, an OS of over

Table 3 Haematological and non-haematological adverse events (NCI CTCAE, version 3.0)

\begin{tabular}{|c|c|c|c|c|}
\hline \multirow[b]{2}{*}{ Type of adverse event } & \multicolumn{2}{|c|}{ wTCF $(n=49)$} & \multicolumn{2}{|c|}{ wTX $(n=55)$} \\
\hline & Grade III, IV or V; No. (\%) & All grades; No. (\%) & Grade III, IV or V; No. (\%) & All grades; No. (\%) \\
\hline Febrile neutropenia & $3(6)$ & $3(6)$ & I (2) & I (2) \\
\hline Anorexia & $9(18)$ & $33(67)$ & $5(9)$ & $28(5 \mathrm{I})$ \\
\hline Nausea & $8(16)$ & $38(78)$ & $8(15)$ & $39(7 \mid)$ \\
\hline Vomiting & $6(12)$ & $23(47)$ & $5(9)$ & $22(40)$ \\
\hline Alopecia & $0(0)$ & $30(61)$ & $0(0)$ & $27(49)$ \\
\hline Rash: hand-foot skin reaction or PPE & $4(8)$ & $16(33)$ & $3(5)$ & $25(45)$ \\
\hline Allergic reaction or hypersensitivity & $0(0)$ & I (2) & $0(0)$ & $2(4)$ \\
\hline Fatigue & $9(18)$ & $45(92)$ & $5(9)$ & $47(85)$ \\
\hline Nail changes & $0(0)$ & $12(24)$ & $2(4)$ & $27(49)$ \\
\hline Watery eyes (tearing) & $0(0)$ & $12(24)$ & $0(0)$ & $18(33)$ \\
\hline Neuropathy: motor & I (2) & I (2) & $0(0)$ & $4(7)$ \\
\hline
\end{tabular}

Abbreviations: $\mathrm{NCl} C \mathrm{CTCAE}=$ National Cancer Institute Common Terminology Criteria for Adverse Events; wTCF=weekly docetaxel plus cisplatin and 5-fluorouracil; $\mathrm{WTX}=$ weekly docetaxel plus capecitabine 
10 months in each arm is encouraging. A recent evaluation of over 1000 patients with advanced oesophagogastric cancer identified several prognostic factors affecting survival outcomes (Chau et al, 2004) (the Royal Marsden Hospital Prognostic Index), which have been validated in a subsequent data set (Chau et al, 2009b). Most patients in each arm in this study had moderate risk factors, previously associated with OS times of 8.6 months, reinforcing the finding that the regimens were clinically active. Palliative benefit was also shown by the improvement in relevant disease-related symptoms, as determined by QLQs.

Several studies in advanced oesophagogastric cancer have shown the activity of docetaxel and capecitabine doublets (Chun et al, 2005; Kim et al, 2005; Lorenzen et al, 2005), although this is not universal (Orditura et al, 2006). As a randomised phase II study, our protocol was not powered for direct efficacy comparisons between the two arms. Nevertheless, the wTCF triplet regimen had the most promising clinical efficacy, especially in terms of response rates, and also for PFS and OS. Although the wTCF triplet was tolerable, it is notable that the improved efficacy was associated with higher rates of grade III/IV diarrhoea, stomatitis, fatigue, and febrile neutropenia than the wTX doublet. A similarly designed weekly docetaxel-based triplet was associated with a comparable toxicity profile and encouraging efficacy in a population in which almost half of the patients had locally advanced disease only (Lorenzen et al, 2007). Other studies have shown similar trends for greater activity from a triplet regimen than from a doublet regimen in advanced gastric cancer (Ajani et al, 2005; Roth et al, 2007). In other diseases, such as colorectal cancer or breast cancer, it is common to sequence doublet therapy or even monotherapy regimens. This may not be so effective an approach for advanced oesophagogastric cancer, as patients often have significant tumour-related symptoms at diagnosis, requiring regimens with the highest levels of activity to achieve significant palliative benefit. Furthermore, for those patients with locally advanced disease (without overt metastatic disease), regimens that result in high response rates may achieve tumour downstaging, thereby facilitating subsequent resection (Lorenzen et al, 2007).

In recent years, oral fluoropyrimidines have been evaluated in oesophagogastric cancer. Capecitabine has been shown to have equivalent activity to 5-FU, with a different safety profile (Cunningham et al, 2008). It is likely that modification of the wTCF regimen by substituting an oral fluoropyrimidine for 5-FU would maintain activity, while potentially improving safety and convenience.

Novel biological targeted agents, such as bevacizumab, cetuximab, and panitumumab, have also improved outcomes in a range of cancers including colorectal, breast, and lung cancer (Hurwitz et al, 2004; Sandler et al, 2006; Jonker et al, 2007; Miller et al, 2007; Van Cutsem et al, 2007). Some of these agents are currently being evaluated in advanced oesophagogastric cancer. Weekly docetaxel-based chemotherapy provides a useful chemotherapy backbone for evaluation of targeted agents, and the AGITG is currently evaluating the efficacy and safety of adding the epidermal growth factor receptor-targeted antibody, panitumumab, to wTCF chemotherapy as treatment for this disease.

\section{ACKNOWLEDGEMENTS}

This study was supported by an unrestricted educational grant by Sanofi-Aventis. Drugs were provided by Sanofi-Aventis and Roche. Numerous individuals from many institutions participated to complete this study. We thank everyone involved for their efforts.

\section{REFERENCES}

Ajani JA, Fodor MB, Tjulandin SA, Moiseyenko VM, Chao Y, Cabral Filho S, Majlis A, Assadourian S, Van Cutsem E (2005) Phase II multi-institutional randomized trial of docetaxel plus cisplatin with or without fluorouracil in patients with untreated, advanced gastric, or gastroesophageal adenocarcinoma. J Clin Oncol 23: 5660-5667

Cascinu S, Graziano F, Barni S, Labianca R, Comella G, Casaretti R, Frontini L, Catalano V, Baldelli AM, Catalano G (2001) A phase II study of sequential chemotherapy with docetaxel after the weekly PELF regimen in advanced gastric cancer. A report from the Italian group for the study of digestive tract cancer. Br J Cancer 84: 470-474

Chau I, Norman AR, Cunningham D, Waters JS, Oates J, Ross PJ (2004) Multivariate prognostic factor analysis in locally advanced and metastatic esophago-gastric cancer-pooled analysis from three multicenter, randomized, controlled trials using individual patient data. J Clin Oncol 22: $2395-2403$

Chau I, Ashley S, Cunningham D (2009b) Validation of the Royal Marsden hospital prognostic index in advanced esophagogastric cancer using individual patient data from the REAL 2 study. J Clin Oncol 27: e3-e4

Chau I, Norman AR, Cunningham D, Oates J, Hawkins R, Iveson T, Nicolson M, Harper P, Seymour M, Hickish T (2009a) The impact of primary tumour origins in patients with advanced oesophageal, oesophago-gastric junction and gastric adenocarcinoma-individual patient data from 1775 patients in four randomised controlled trials. Ann Oncol 20: $885-891$

Chau I, Starling N, Cunningham D, Oates J, Iveson T, Nicolson M, Hawkins R, Hickish T, Seymour M, Norman A (2007) Does histology influence outcome in advanced oesophagogastric (OG) cancer? Individual patient data from 1680 patients on three randomised controlled trials (RCT). J Clin Oncol 25: 15001

Chen LT, Liu TW, Wu CW, Chung TR, Shiah HS, Jan CM, Liu JM, WhangPeng J, Chang JY (2002) A phase I study of weekly docetaxel, 24-hour infusion of high-dose fluorouracil/leucovorin and cisplatin in patients with advanced gastric cancer. Oncology 63: 239-247
Chun JH, Kim HK, Lee JS, Choi JY, Hwangbo B, Lee HG, Park SR, Choi IJ, Kim CG, Ryu KW, Kim YW, Lee JS, Bae JM (2005) Weekly docetaxel in combination with capecitabine in patients with metastatic gastric cancer. Am J Clin Oncol 28: $188-194$

Cunningham D, Starling N, Rao S, Iveson T, Nicolson M, Coxon F, Middleton G, Daniel F, Oates J, Norman AR, Upper Gastrointestinal Clinical Studies Group of the National Cancer Research Institute of the United Kingdom (2008) Capecitabine and oxaliplatin for advanced esophagogastric cancer. $N$ Engl J Med 358: 36-46

Engels FK, Verweij J (2005) Docetaxel administration schedule: from fever to tears? A review of randomised studies. Eur J Cancer 41: 1117-1126

Glimelius B, Hoffman K, Graf W, Haglund U, Nyrén O, Påhlman L, Sjödén PO (1995) Cost-effectiveness of palliative chemotherapy in advanced gastrointestinal cancer. Ann Oncol 6: 267-274

Hurwitz H, Fehrenbacher L, Novotny W, Cartwright T, Hainsworth J, Heim W, Berlin J, Baron A, Griffing S, Holmgren E, Ferrara N, Fyfe G, Rogers B, Ross R, Kabbinavar F (2004) Bevacizumab plus irinotecan, fluorouracil, and leucovorin for metastatic colorectal cancer. $N$ Engl J Med 350: 2335-2342

Jonker DJ, O'Callaghan CJ, Karapetis CS, Zalcberg JR, Tu D, Au HJ, Berry SR, Krahn M, Price T, Simes RJ, Tebbutt NC, van Hazel G, Wierzbicki R, Langer C, Moore MJ (2007) Cetuximab for the treatment of colorectal cancer. $N$ Engl J Med 357: $2040-2048$

Kamangar F, Dores GM, Anderson WF (2006) Patterns of cancer incidence, mortality, and prevalence across five continents: defining priorities to reduce cancer disparities in different geographic regions of the world. $J$ Clin Oncol 24: 2137-2150

Kim JG, Sohn SK, Kim DH, Baek JH, Sung WJ, Park JY, Kim TB, Jung HY, Yu W, Lee KB (2005) Phase II study of docetaxel and capecitabine in patients with metastatic or recurrent gastric cancer. Oncology 68: 190-195

Lee JJ, Han JY, Lee DH, Kim HY, Yoon SM, Lee SY, Lee JS (2006) A phase II trial of docetaxel plus capecitabine in patients with previously treated non-small cell lung cancer. Jpn J Clin Oncol 36: 761-767 
Lorenzen S, Duyster J, Lersch C, von Delius S, Hennig M, Bredenkamp R, Peschel C, Lordick F (2005) Capecitabine plus docetaxel every 3 weeks in first- and second-line metastatic oesophageal cancer: final results of a phase II trial. Br J Cancer 92: 2129-2133

Lorenzen S, Hentrich M, Haberl C, Heinemann V, Schuster T, Seroneit T, Roethling N, Peschel C, Lordick F (2007) Split-dose docetaxel, cisplatin and leucovorin/fluorouracil as first-line therapy in advanced gastric cancer and adenocarcinoma of the gastroesophageal junction: results of a phase II trial. Ann Oncol 18: 1673-1679

Miller K, Wang M, Gralow J, Dickler M, Cobleigh M, Perez EA, Shenkier T, Cella D, Davidson NE (2007) Paclitaxel plus bevacizumab versus paclitaxel alone for metastatic breast cancer. $N$ Engl J Med 357: 2666-2676

Mrozek E, Ramaswamy B, Young D, Rhoades CA, Kendra K, Allen J, Moore T, Hauger M, Watson H, Merriman N, Nadella P, Villalona-Calero M, Shapiro CL (2006) Phase II study of weekly docetaxel and capecitabine in patients with metastatic breast cancer. Clin Breast Cancer 7: $141-145$

Nadella P, Shapiro C, Otterson GA, Hauger M, Erdal S, Kraut E, Clinton S, Shah M, Stanek M, Monk P, Villalona-Calero MA (2002) Pharmacobiologically based scheduling of capecitabine and docetaxel results in antitumor activity in resistant human malignancies. J Clin Oncol 20: 2616-2623

Orditura M, Martinelli E, Galizia G, Carlomagno C, Aurilio G, Vecchione L, Lieto E, De Placido S, Catalano G, Ciardiello F, De Vita F (2006) Weekly docetaxel and capecitabine is not effective in the treatment of advanced gastric cancer: a phase II study. Ann Oncol 17: 1529-1532

Roth AD, Fazio N, Stupp R, Falk S, Bernhard J, Saletti P, Köberle D, Borner MM, Rufibach K, Maibach R, Wernli M, Leslie M, Glynne-Jones R,
Widmer L, Seymour M, de Braud F, Swiss Group for Clinical Cancer Research (2007) Docetaxel, cisplatin, and fluorouracil; docetaxel and cisplatin; and epirubicin, cisplatin, and fluorouracil as systemic treatment for advanced gastric carcinoma: a randomized phase II trial of the Swiss Group for Clinical Cancer Research. J Clin Oncol 25: $3217-3223$

Sandler A, Gray R, Perry MC, Brahmer J, Schiller JH, Dowlati A, Lilenbaum R, Johnson DH (2006) Paclitaxel-carboplatin alone or with bevacizumab for non-small-cell lung cancer. $N$ Engl J Med 355: 2542 - 2550

Thuss-Patience PC, Kretzschmar A, Repp M, Kingreen D, Hennesser D, Micheel S, Pink D, Scholz C, Dorken B, Reichardt P (2005) Docetaxel and continuous-infusion fluorouracil versus epirubicin, cisplatin, and fluorouracil for advanced gastric adenocarcinoma: a randomized phase II study. J Clin Oncol 23: 494-501

Van Cutsem E, Peeters M, Siena S, Humblet Y, Hendlisz A, Neyns B, Neyns B, Canon JL, Van Laethem JL, Maurel J, Richardson G, Wolf M, Amado RG (2007) Open-label phase III trial of panitumumab plus best supportive care compared with best supportive care alone in patients with chemotherapy-refractory metastatic colorectal cancer. J Clin Oncol 25: $1658-1664$

Van Cutsem E, Moiseyenko VM, Tjulandin S, Majlis A, Constenla M, Boni C, Rodrigues A, Fodor M, Chao Y, Voznyi E, Risse ML, Ajani JA, V325 Study Group (2006) Phase III study of docetaxel and cisplatin plus fluorouracil compared with cisplatin and fluorouracil as first-line therapy for advanced gastric cancer: a report of the V325 Study Group. J Clin Oncol 24: $4991-4997$ 